\title{
Exploring the Effectiveness of a Reading-dictation Task in Promoting Chinese Learning as a Second Language
}

\author{
$\mathrm{Liu} \mathrm{Li}^{1}$ \\ ${ }^{1}$ Faculty of English Language Education, Guangdong University of Foreign Studies, China \\ Correspondence: Liu Li, Faculty of English Language Education, Guangdong University of Foreign Studies, \\ No.2 North Baiyun Road, Baiyun District, Guangzhou, China. Tel: 86-136-1144-2506. E-mail: \\ kristenliul@hotmail.com
}

Received: October 30, 2019

Accepted: November 26, 2019 Online Published: January 8, 2019

doi:10.5539/hes.v10n1p100

URL: https://doi.org/10.5539/hes.v10n1p100

\begin{abstract}
Dictation has long been recognized as a valid testing device and practical teaching technique in second language (L2) teaching and research. Yet recent years have witnessed an increasing use of integrated tasks in language education. This paper attempts to combine dictation with a reading activity and thereby explores the effectiveness of a reading-dictation integrated task, as compared to a dictation-only task in facilitating Chinese learning as a L2. Results of a quasi-experimental study showed that in reading-dictation, participants produced a higher number of correct characters and made less use of pinyin for support; homophone errors and comprehension errors were noticeably reduced. In addition, feedbacks from an interview verified participants' positive attitudes towards the reading-dictation task. Pedagogical implications of this study were subsequently discussed, in relation to Chinese L2 teaching in general and orthography teaching in particular.
\end{abstract}

Keywords: reading-dictation, integrated task, effectiveness, Chinese L2 teaching

\section{Introduction}

The use of dictation in second/foreign language education can be dated back several decades ago. Dictation is widely adopted as a means of language testing in the 70s and 80s. It is documented that dictation correlates with learners' overall language proficiency more strongly than other forms of testing, such as vocabulary, close or writing test (Oller and Streiff 1975; Savignon 1982; Taylor 1980; Kaga 1991). Although some researchers claimed that dictation lacks the communicative feature in real human languages and therefore may "measure very little of language" (Lado 1961; Jones 1977), others have pointed out that dictation has the merit of testing comprehension in context based on learners' internalized grammar' (Oller 1979; Cohen 1980; Morris 1983; Stansfield 1985). Recent studies have examined the effectiveness of using dictation as a teaching technique and provided evidence that dictation as a form of regular teaching practice can improve learners' overall language competence and vocabulary accuracy in the long term (Rahimi 2008; Pyun and Lee-Smith 2011; Qu 2012). However, the efficacy of dictation in language learning has not been fully examined and its application in actual language teaching is still fairly limited. This study, therefore, intends to explore the effects of an alternative form of dictation in enhancing the learning of Chinese as a second language (L2). Specifically, it will test the effectiveness of an integrated reading-dictation task as compared to a traditional dictation-only task in facilitating learners' overall performance and orthographical accuracy.

\section{Literature Review}

\subsection{Dictation in L2 Education}

Chinese as a second/foreign language has received global popularity in recent years. Learning of Chinese characters, however, poses enormous difficulty for L2 learners, especially those whose native language are alphabetical (Shen 2004; Chen et al. 2014). Chinese characters are picture-shaped and the connection between the sounds and the forms often remains opaque and complex for non-natives. To make the situation even worse, Chinese is never short of homophones. One syllable may be represented by several characters, depending on the specific meaning, as 输 $s h u$ 'enter' in 输入 shu-ru 'inputs', 书 shu 'book' in 书本 shu-ben 'books' or 舒 shu 'easy' in 舒服 shu-fu 'comfortable'. It is observed that learners often fail to recognize some characters in spoken communication even though they might as well "know" the words. More sufficient contextual information is 
apparently needed for learners to activate the right characters, especially those with similar sounds but different meanings.

Dictation tasks serve well in this aspect as it combines listening comprehension, spelling accuracy, and phonetic processing all in one meaningful context. To complete a dictation task, learners need to distinguish different sounds, make selection of lexis, constantly formulate expectancies concerning the incoming sounds and information based on their internalized grammar of the language, and record the speech in written forms as fast as they can. Oller was among the first scholars to offer evidence that dictation can measure one's overall language proficiency and pointed out that far from making phonetic echoing passively, learners are instead involved in "an active analysis-by-synthesis process" during dictating (Oller and Streiff 1975). Other researchers also emphasized the multiple values of dictation as a teaching technique. Morris (1983) mentioned that dictation motivates learners in an active reinterpretation of the aural material and can be used to improve listening skills and comprehension and to avoid structural and spelling errors. It therefore should be regarded as an important learning activity to develop students' accuracy in both listening and writing. Based on their long-term teaching practice, Davis and Rinvolucri (1988) revealed that dictation is particularly purposeful for "learning language in which the relationship between the sound system and the spelling is complex". Pyun and Lee-Smith (2011) even developed and implemented both on-line and in-class dictation programs to help Korean heritage learners to improve orthographic accuracy. The results uncovered the merits of dictation as a teaching and learning device, especially to raise learners' awareness on orthographic errors and become more sensitive on the sound-form relationship of symbols. However, traditional dictation task is not readily welcomed by L2 learners as they may complain about the tedious and burdensome workload involved (Pyun and Lee-Smith 2011).

\subsection{Use of Integrated Tasks}

Recent years have witnessed an increasing shift from simple tasks towards integrated ones in the practice of L2 education. Integrated tasks have been constantly used in high-stake tests such as IELTS and TOEFL. Reading-to-write or listening-to-write tasks are shown to be more beneficial for test takers in providing them with more content and language supports than the independent writing task (Cumming et al. 2005; Plakans 2008). Nevertheless, how to use these integrated tasks in language classroom still remains an under-researched area.

The continuation task, one form of integrated tasks proposed and developed by C. Wang (2012, 2014, 2015), has proved to be highly efficient and appealing in actual language learning and teaching practice, as shown in reading-writing, reading-speaking and even reading-translating tasks. These tasks are simple to implement. Taking the reading-writing continuation task as an illustration. Teachers can present the learners a text of an unfinished story, with the ending removed; and learners are supposed to read and understand the story fully before continuing and completing it in writing with coherence and logic. The theoretical assumption is that production coupled with comprehension may lead to increased alignment, the underlying mechanism for successful communication (Pickering and Garrod 2004, 2006). The asymmetry between comprehension and production expedites learners to employ the provided linguistic forms in the source text into their own production under a meaningful context. Like in a dialogue where interlocutors coordinate with each other linguistically, learners interact with the original texts dynamically in the continuation task (Wang and Wang 2014; Zhang 2017). Empirical studies have shown that in the continuation task designed for English L2 learners, alignment was found between the reading text and learners' writing products in terms of content and language use. Learners' overall performance on writing was significantly improved and language mistakes including grammatical and lexical errors were noticeably reduced in the continuation task than in the writing-only task (Wang and Wang 2015; Jiang and Tu 2016; Chen et al. 2017) .

Stimulated by the continuation task, this study adopts an alternative form --- a reading-dictation task, to investigate whether it can better enhance the overall dictation performance, and hence the L2 acquisition, for Chinese L2 learners. Different from a dictation-only task, in which learners dictate a passage from the beginning to the end, a reading-dictation task offers learners a source text of an incomplete story before requiring them to listen to and write down the rest of the story. When dictation is coupled with reading, more interaction will rise up between the learner and the source text, leading to better comprehension of the whole story and expectedly better performance of the subsequent dictation. According to Zwaan and Radvansky's situational model (1998), text comprehension involves dimensions of time, space, causality, intentionality and reference to main individuals. Reading the source text before dictation will help learners to construct the situation model by noticing the various dimensions of a text and therefore better follow the remaining parts of the text presented aurally. 


\section{The Present Study}

\subsection{Research Questions}

To evaluate the efficacy of the reading-dictation integrated task, three research questions were raised accordingly in the present study.

1) Is $L 2$ learners' overall performance better in the reading-dictation task compared to the dictation-only task?

2) If yes, in which aspects learners' overall performance is better?

3) How do learners evaluate the two dictation tasks?

\subsection{Participants}

27 oversea students in a university in mainland China volunteered to take part in the study. They were 18 females and 9 males of different nationalities, with 15 students coming from Thailand, 6 from Malaysia, 5 from India, and 1 from Britain. Their age ranged from 19 to 25 years old, with an average age of 21. Most of them had passed the HSK-4 (18 students); some had passed HSK-5 (6 students) and HSK-6 (3 students).

\subsection{Materials and Methods}

A quasi-experiment and a semi-structured interview were adopted in this study. For the quasi-experimental design, learners' performance on the dictation-only task and the reading-dictation task were compared. As regard to the interview, learners' opinions and attitudes towards the two kinds of dictation were collected, especially in relation to their Chinese learning practice.

Two short passages parallel in length and difficulty level were chosen as the dictation material (See Appendix). Passage 1 has 462 characters and gives an account of two successful salesmen in an insurance company. Passage 2 describes the daily life of a taxi-driver who works from morning till dawn in 463 words. In the diction-only task, the whole passage of 1 and 2 was dictated from the beginning to the end. In the reading-dictation task, each passage was divided into two parts, the reading part and the dictation part. For passage 1, the dictation part included 154 characters of the end of the text; and for Passage 2, there were 160 characters. Learners were instructed to read the story first and then to dictate the remaining of the story.

In addition, in the two passages, five identical compound words appeared both in the reading text and the subsequent dictation text. In Passage 1, these five compounds were 来意 laiyi 'purpose for visiting,' 报价 baojia 'offer, quoted price', 打动 dadong 'touch', 接受 jieshou 'accept', 方法 fangfa 'strategy'. In Passage 2, these compounds were:司机 siji 'driver', 生意 shengyi 'business', 厉害 lihai 'seriously', 浪费 langfei 'waste' and 忙碌 manglu 'busy'. The compounds were presented in the passage with blackened forms to raise learners' awareness. It is expected that the reading-dictation task may particularly enhance the accuracy rate of these repeated compounds.

\subsection{Procedures}

The experiment consisted of four sessions and was completed in four weeks. Each passage was alternately presented in two tasks: reading-dictation and dictation-only and the order was counterbalanced. In the first week, participants completed the reading-dictation task of passage 1 . They first read the source text (308 characters) in a period of 15 minutes, during which they were encouraged to read more than once and to look up for the unfamiliar words in a dictionary for full understanding. After reading, the text was collected and participants began to dictate the rest of the passage (154 characters), which took about 20 minutes. In the second week, participants completed the dictation-only task of passage 2 from the beginning to the end. The total time spent on it was about 35 minutes. Tasks of dictation-only of passage 1 and reading-dictation of passage 2 were then performed respectively in the third and the fourth week. See the flow chart of Figure 1 for a detailed description of test procedures.
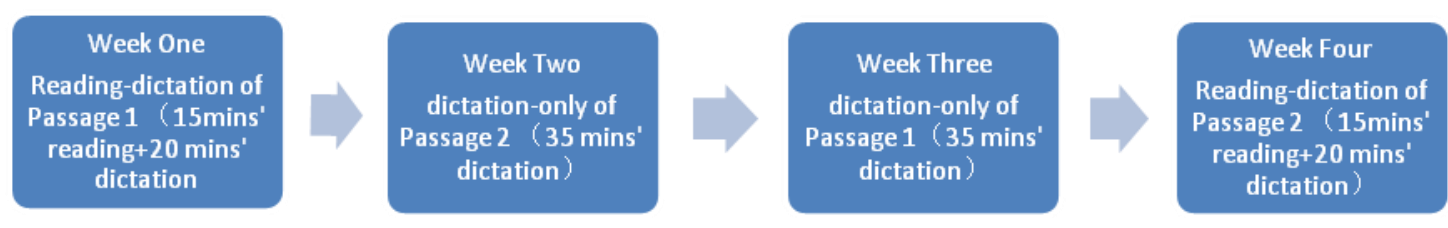

Figure 1. A flow chart of dictation test procedures

The dictations were recorded in advance chunk by chunk. Each chunk was determined mainly by the original 
clauses, except when the clause was too long and was further segmented based on semantic units. In the reading-dictation task, there were a total of 22 chunks in the dictation part in Passage 1 and 21 chunks in Passage 2. In the dictation-only task, there were altogether 66 chunks in Passage 1 and 58 chunks in Passage 2. The length of each chunk varied from 4 to 14 characters, with an average length of 7 . According to Oller (1979), such a length of sequence is sufficient to challenge dictation-takers' limits of short-term memory and a deeper level of language processing can be assured.

Following Oller's suggested procedures, each dictation was read three times. In the first and the third time, the story was read in the speed of a normal conversation. In the second time, the story was read chunk by chunk, with sufficient pauses between each chunk for learners to take each character down. Due to the specific orthographic complexity of Chinese characters, each chunk was read two times to give students enough time for writing. The time for pauses was decided by the time dictated to a native speaker plus an extra 10 seconds. Learners were informed that they could write in pinyin in case they were unable to write the characters.

\subsection{Scoring}

To make reasonable comparisons, we scored only the part identical in both the dictation-only and the reading-dictation task, i.e. the ending part of 154 characters for Passage 1 and the 160 characters for Passage 2. So, there are 4 versions of dictation in total, a reading-dictation version and a dictation-only version for each passage.

The present study adopted a strict standard in assessment of participants' dictation considering that their language proficiency is generally upper-intermediate or even above. The scorings focused on three aspects in the dictation text: the number of accurate characters, the number of pinyin and the number of incorrect characters. Missing characters are counted as incorrect ones and characters produced in the dictation but do not occur in the original text are ignored. So, we can see that the number the correct characters actually can be figured out via the total number of characters in the original text subtracted the number of incorrect characters and pinyin. For instance, if participant A wrote down 33 pinyin, and wrongly spelt 24 characters for Passage 1, then the number of correct characters can be calculated as: $154-33-24=97$. Based on this criteria, the maximum number of correct characters in Passage 1 dictation would be 154, and in Passage 2, 160.

In addition, the accuracy of the five repeated compounds in each passage was rated as well. Each correctly spelt compound is given 1 point (no point if only one character of a compound is correct). The maximum score is thus 5.

\section{Resutls and Discussion}

\subsection{Results of the Dictation Experiments}

Among the 27 participants, one failed to complete the four testing sessions. Two other learners wrote down only pinyin in all dictation sessions, making it impossible to rate the papers. So, these three participants were deleted and a total of 24 valid testing papers were retrieved. Table 1 shows the average scores in diction-only and reading-dictation with Passage 1 and 2 as a whole (a sum of 314 characters) according to the number of incorrect characters, pinyin and correct characters.

Table 1. Average Scores (and Standard Deviations) in Reading-dictation and Dictation-only Task

\begin{tabular}{llll}
\hline & Incorrect characters & pinyin & Correct characters \\
\cline { 2 - 4 } Reading-dictation & $29.79(21.11)$ & $27.83(24.73)$ & $256.37(40.81)$ \\
Dictation-only & $32.54(18.02)$ & $43.79(34.59)$ & $237.67(46.54)$ \\
\hline
\end{tabular}

We can see that generally speaking, more spelling errors and pinyin occurred in the dictation-only task whereas participants produced more correct characters in the reading-dictation task. A paired T-test was then conducted and the results revealed a significant difference in the number of correct characters between the two tasks $(\mathrm{t}=$ $6.940 ; \mathrm{df}=23, \mathrm{p}=.000$ ). That is, participants' overall performance was much better in the reading-dictation than in the dictation-only task. The difference in terms of use of pinyin was also significant $(\mathrm{t}=-4.788 ; \mathrm{df}=23, \mathrm{p}$ $=.000$ ) between the two tasks. Participants were less likely to turn to the backup of pinyin in performing reading-dictation task, an indicator that the source text in reading-dictation did offer extra language supports for better outcomes.

Now let's look at participants' performance on each passage in the two tasks. Table 2 lists the average number of pinyin, incorrect and correct characters in Passage 1 and 2 according to task types (a total of 154 characters in Passage 1 and 160 characters in Passage 2). 
Table 2. Average Scores (and SDs) of Passage 1 and 2 in reading-dictation and dictation-only task

\begin{tabular}{lllllll}
\hline & \multicolumn{2}{l}{ Reading-dictation } & \multicolumn{3}{l}{ Dictation-only } \\
\cline { 2 - 7 } & $\begin{array}{l}\text { Incorrect } \\
\text { characters }\end{array}$ & pinyin & $\begin{array}{l}\text { Correct } \\
\text { characters }\end{array}$ & $\begin{array}{l}\text { Incorrect } \\
\text { characters }\end{array}$ & pinyin & $\begin{array}{l}\text { Correct } \\
\text { characters }\end{array}$ \\
\hline Passage 1 & $14.21(10.63)$ & $15.63(14.18)$ & $124.17(22.32)$ & $18.83(13.51)$ & $26.30(21.04)$ & $108.88(28.44)$ \\
Passage 2 & $15.58(12.09)$ & $12.21(12.06)$ & $132.21(18.83)$ & $13.71(6.67)$ & $17.50(14.18)$ & $128.79(19.24)$ \\
\hline
\end{tabular}

It can be seen that in both passages, participants made less spelling mistakes and produced less pinyin in the reading-dictation task, hence higher numbers of correct characters. Paired T-tests were then conducted to measure the task effect in the two passages respectively. For Passage 1, results showed that the number of correct characters in the reading-dictation task was significantly higher $(\mathrm{t}=7.407, \mathrm{df}=23, \mathrm{p}=.000)$. T-tests results in Passages 2 also showed similar tendency $(\mathrm{t}=2.407 ; \mathrm{df}=23, \mathrm{p}=.024)$. These results imply that participants' overall performance in the reading-dictation task was better than that in the dictation-only task regardless of task presentation sequence. In addition, the difference between the number of pinyin in the two tasks was also significant in both Passage $1(\mathrm{t}=-4.008, \mathrm{df}=23, \mathrm{p}=.001)$ and Passage $2(\mathrm{t}=-3.153, \mathrm{df}=23, \mathrm{p}=.004)$, which implies that participants had to turn to the expediency of pinyin assistance with higher frequency in the dictation-only task.

One thing that needs our particular attention is that for Passage 2, less incorrect characters were found in the dictation-only than in the reading-dictation task (13.71:15.58). One possible reason for this might be related to the topic of this passage, the daily life of a taxi-driver, which is more familiar to oversea students than the topic in Passage 1, two successful salesmen in an insurance company. Studies on reading-writing continuation task have shown that content and topic of reading text exerted impact on learners' writing text (Xue, 2013). It seems familiarity with the source text increased participants' attempt to produce more characters while using less pinyin, which expectedly resulted in a higher chance of committing various errors. This, however, provides further evidence for the supportive role played by reading before dictating.

We then compared the accuracy of the five compounds reoccurring in the reading and the dictation part. Table 3 gives a record of the correct rates of the five compound in terms of task type.

Table 3. Average scores (and SDs) of five compounds in reading-dictation and dictation-only task

\begin{tabular}{llll}
\hline & Passage 1 & Passage 2 & Total \\
\cline { 2 - 4 } Reading-dictation & $3.13(1.62)$ & $3.21(1.63)$ & $6.33(3.01)$ \\
Dictation-only & $2.42(1.53)$ & $2.17(1.52)$ & $4.59(2.78)$ \\
\hline
\end{tabular}

Two Wilcoxon tests was conducted and the results showed significant difference in the accuracy rates of the five compounds between reading-dictation and dictation-only in both Passage $1(Z=-3.697, p=.000)$ and Passage 2 $(\mathrm{Z}=-1.971, \mathrm{p}=.049)$. Reading-dictation better facilitates the correct production of these re-occurring compounds. This suggests that when participants are given the chance to read a particular word right before the dictation, the probability of noting it down correctly increased dramatically. Reading-dictation offers a continuous context for learners to understand and then to retrieve the words in a meaningful way. As Wang (2003, 2014) pointed out, linguistic knowledge needs to integrate with contextual knowledge to guarantee proper and fluent use of language structures. Putting target vocabulary into meaningful contexts helps learners to construct the appropriate link between a form and its function.

\subsection{Common Errors in the Dictation}

A close analysis on the errors in the two tasks was performed as well. We first categorized these errors into several types and then made a comparison of each error type in relation to the two dictation tasks.

Three major types of written errors were identified. The first type can be called spelling errors, including cases of missing a stroke, adding extra stokes or wrong forms of radicals. This type of errors is reported as particularly pervasive among L2 Chinese learners (Yan, 2013). Examples of this type in the dictation include: *最选 zui-xuan 'the-select', which should be 最先 zui-xian 'the first'; 成功 cheng-gong 'succeed', misspelt as *成工 cheng-gong 'make-work;' and 越来 yue-lai 'more and more' as *走成来, etc.

The second type of errors is homophone errors, in which participants confounded characters with similar sounds but different meanings, a thorny issue often reported in Chinese L2 teaching and research (Chen et al, 2014; Cheng and Chiu, 2018). For instance, 除了 chu-le 'except' was wrongly taken as 出了 chu-le 'exit', 挣钱 
zheng-qian 'earn money' as 正钱 zheng-qian 'right-money', 忙碌 mang-lu 'busy' as 忙路 mang-lu 'busy-road', etc.

The third type is identified as comprehension errors. When participants could not understand the dictation text well, they produced linguistic forms which distorted the original meaning. For example, 吃盒饭 chi-he-fan 'have-box-lunch' was incorrectly understood as 适合饭 shi-he-fan 'fit-lunch' and 红着脸 hong-zhe-lian 'with-red-face' might be misunderstood as 红这里 hong-zhe-li 'red-here', etc. Such errors are what Morris referred to as meaning errors in her study, in which "a police spokesman" may be taken as "a police postman".

Figure 2 shows the proportion of each error type in reading-dictation and dictation-only tasks with Passage 1 and 2 as a whole. It can be seen that the reading-dictation task noticeably reduced Type Two and Type Three errors, i.e. homophone errors (27\%:34\%) and comprehension errors (38\%:44\%). This means that reading-dictation effectively helped participants in distinguishing homophones, which is of particular value considering the large number of single-syllable homophones in Chinese. It also improved participants' listening performance and enhanced their comprehension of the original text. It is only possible to contribute these differences in error distribution to the reading of the source text, which participants were supposed to rely on in support of their dictating, especially in figuring out the proper linguistic forms with the right meaning.

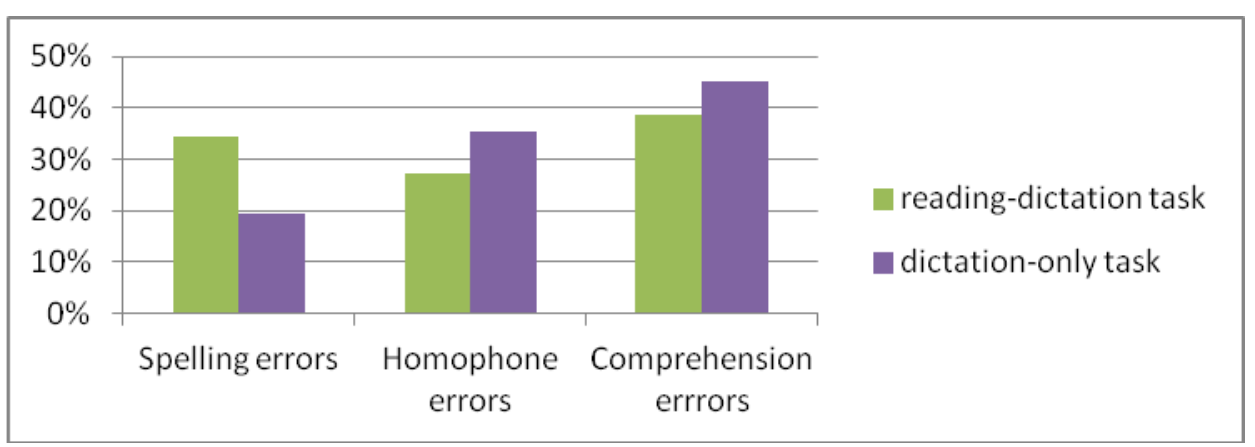

Figure 2. Error distribution in reading-dictation and dictation-only tasks

It is also true that more Type One errors, spelling errors, were found in reading-dictation (34\%:19\%). This is because participants made use of dramatically less pinyin in their writing (see Table One for reference), and managed to produce more characters in their output, which consequently led to a higher probability of getting errors. The higher number of spelling errors, as a matter of fact, reflects the fact that learners' willingness and ability to note down characters was improved in the reading-dictation task.

\subsection{Results of the Interview}

At the end of the dictation experiments, we interviewed 6 volunteer participants for their feedbacks on the two tasks. They were three females and three males, and were invited to provide answers for two questions: which dictation task do you prefer and for what reasons? Their responses were recorded and then categorized, which can be summarized under the following headings.

a. Preference to Reading-dictation: Almost all interviewees expressed their preference of reading-dictation to the dictation-only task as they considered the former presented useful cues for better predictions and hence reduced their anxiety in dictating. One participants related that "I prefer to read first and then to dictate. I can guess what will follow next." Another participant recalled that "I can practice the spelling of some characters and I think it is a very interesting class activity. I noted down several words in the reading part, such as 忙碌 manglu 'busy' and 浪费 langfei 'waste'. It really helped in my dictation part. I feel terrific." Moreover, one participant gave comments via complaining about the workload involved in the dictation-only task, "My arms are aching when I finish the writing. So tiring!"

One participant, on the other hand, claimed that she actually preferred the dictation-only task as she found the reading-dictation did not pose enough challenge. Considering the fact that she has passed HSK 6, the dictation with longer length and higher difficulty might serve her the best. This, nevertheless, provides indirect evidence that integrated reading-dictation task does offer extra supports for the dictating performance indeed.

b. Reading-dictation as an effective learning tool: Respondents considered reading-dictation as a useful learning tool to practice their listening while following a complete story, to consolidate their spelling of characters, and raise the awareness of the differences between homophones in a meaningful context. One participant commented 
that "It puts reading, listening and writing all together. For me, it is particularly beneficial to practice the spelling of characters and how to use these characters in a text." He further recalled that "I learned some new words in the task. For example, it's the first time I encounter the word 报价 bao-jia 'price quote'. This is a useful activity to learn new words." Another participant also gave a specific example on his learning experience. "Reading-dictation is very useful to tell the difference between homophones. For example, when I first heard 书 画 shu-hua 'calligraphy-painting', I did not realize what it really meant and misunderstood it as a kind of flower (as 画 hua 'painting' and 花 hua 'flower' sound similarly in Chinese). Then I recalled 足球 zu-qiu 'football' in the reading part, and I realized it talked about hobbies. So I came to understand 书画 shu-hua as calligraphy and painting." Other participants suggested that "If I do such reading-dictation every day, it would be very helpful for my Chinese." "It reminds of the fact that I just cannot get some simple words right. But it is far more interesting than just memorizing words alone." "Dictation helps me realize my wrong pronunciations of many words. I need to practice my listening more."

\section{Conclusion and Pedagogical Implications}

Dictation has been held as a teacher-centered activity and mainly utilized as a language testing device in language education (Oller 1979; Stansfield 1985). Its potential usefulness in classroom teaching, however, has not been properly recognized and exploited (Pyun and Lee-Smith 2011). The present empirical study demonstrates the effectiveness of an integrated dictation task, namely the reading-dictation task, in facilitating the learning of Chinese as a L2. The results of the quasi-experimental study reveal that in comparison to dictation-only task, reading-dictation generates significantly higher number of correct characters with less employment of pinyin in the dictation output. Results from the interview feedback also manifest learners' preference and favorable appraisal for this task.

In the reading-dictating process, multiple skills are involved as reading, listening and writing are all combined together. Since the production of dictation is coupled with comprehension of the text, primarily learners need to interact with the source text, such as re-reading the text, paying special attention to unfamiliar characters, inferring the rest of the story, etc. "Where there is interaction, alignment and hence learning will occur" (Wang and Wang 2014 ). That is, alignment occurs as the learners tries to get meanings from the source text. This alignment may consists of two levels: linguistic and situational levels. At the situational level, the source text provides learners with necessary information for successful comprehension, such as time, space, causality, intentionality and reference to main individuals (Pickering and Garrod 2006). This constructed situation model can be relied on in interpreting and following up the dictation text, creating better overall output. At the linguistic level, reading the source text may raise learners' noticing of particular words and activate their passive vocabulary. This can explain why participants produced more correct characters and used less pinyin in their dictation output. This alignment effect also improves learners' overall listening comprehension of the dictating text, especially in identifying homophones.

When no source text is provided as in the dictation-only task, self-alignment occurs in which learners' own linguistic knowledge is drawn on to construct the situation model for comprehension and dictating. Consequently more inter-linguistic errors and convenient use of pinyin were witnessed in the dictation-only task, as reported in the results.

Attention and noticing have been pointed out as key elements in vocabulary retention and acquisition (Nation 2001; Robinson et al. 2002). Five compounds in the reading text are highlighted and supposed to draw extra attention from the participants, as one participants commented, "I am aware of the bold characters. I even wrote down the words on the edge to make sure I can spell them correctly". The higher accuracy rate of these compounds in reading-dictation in contrast to the dictation-only task indicate that this extra attention is an essential component for word retention. The coupling of comprehension with production in reading-dictation raises learners' awareness and noticing of the target words in the reading part, hence a better chance of being memorized and maintained in the output.

Findings in this study hold a number of implications for the practice of Chinese teaching as a L2. First, reading-dictation offers an effective and appealing teaching technique to raise learners' awareness on the orthographical feature of Chinese characters and to improve spelling accuracy, especially for those characters with similar sounds but different meanings. Second, reading-dictation can also be a useful classroom activity to improve listening skills and reduce distortions in comprehension. Third, reading-dictation provides an alternative method to introduce or consolidate the learning of particular compounds via repetition under meaningful context. As a reminder in teaching practice, the selection of material in reading-dictation is supposed to be stories of interest and relevance to learners so as to boost and maintain their motivation in learning. 
Finally, this study has several limitations. Due to practical reasons of recruitment, the present study collected data of the two dictation tasks at alternate weeks from the same group of participants. The time gap between sessions may not be sufficient to cancel out the carryover effects from one task to the other. In addition, the scoring principle and procedure of dictation texts may also need re-examination so as to validly reflect the differences in learner performance. Moreover, a longitudinal study on the effect of reading-dictation would be desirable to demonstrate its advantages and long-term efficiency, which exactly defines our research directions in the future.

\section{References}

Chen, M. P., Li-Chun, W., Hsiu-Ju, C., \& Yu-Chu, C. (2014). Effects of type of multimedia strategy on learning of Chinese characters for non-native novices. Computers and Education, 70(1), 41-52. https://doi.org/10.1016/j.compedu.2013.07.042

Chen, X. N., \& Feng, T. (2017). Assessing the effects of word exposure frequency on incidental vocabulary acquisition from reading and listening. Chinese Journal of Applied Linguistics, 40(1), 56-73. https://doi.org/10.1515/cjal-2017-0004

Cheng, F.-W., \& Miao-chin, C. (2018). Scaffolding Chinese as a second language writing through a systemic functional linguistics approach. System, 72(1), 99-113. https://doi.org/10.1016/j.system.2017.11.003

Cohen, A. (1984). On taking language tests: what the students reports. Language Testing, 1(1), 70-81. https://doi.org/10.1177/026553228400100106

Cumming, A., Robert, K., Kyoko, B., Usman, E., Keanre, E., \& Mark, J. (2005). Differences in written discourse in writing-only and reading-to-write prototype tasks for next generation TOEFL. Assessing Writing, 10(1), 5-43. https://doi.org/10.1016/j.asw.2005.02.001

Davis, P., \& Mario, R. (1988). Dictation: New methods, new possibilities. Cambridge: Cambridge University Press.

Gu, X. D., \& Shi, C. Y. (2012). A retrospective study on test-takers' cognitive and metacognitive Processes in taking a compound dictation. Chinese Journal of Applied Linguistics, 35(4), 400-420. https://doi.org/10.1515/cjal-2012-0030

Jiang, L., \& Tu, M. W. (2016). (Effects of the continuation task on L2 vocabulary learning). Modern Foreign Languages, 39(6), 819-829.

Kaga, M. (1991). Dictation as a measure of Japanese proficiency. Language Testing, 8(2), 112-124. https://doi.org/10.1177/026553229100800202

Lado, R. (1961). Language Testing. New York: McGraw-Hill.

Lee, C. H., \& Slava, K. (2011). Effectiveness of different Pinyin Presentation Formats in Learning Chinese Characters: A cognitive load perspective. Language Learning, 61(4), 1099-1118. https://doi.org/10.1111/j.1467-9922.2011.00666.x

Morris, S. (1983). Dictation --- a technique in need of reappraisal. ELT Journal, 37(2), 121-126. https://doi.org/10.1093/elt/37.2.121

Nation, P. (2001). Learning Vocabulary in Another Language. Cambridge: Cambridge university Press. https://doi.org/10.1017/CBO9781139524759

Oller, J. (1979). Language Test at School. London: Longman.

Oller, J., \& Virginia, S. (1975). Dictation: A test of grammar-based expectancies. ELT Journal, 30(1), 25-36. https://doi.org/10.1093/elt/XXX.1.25

Pickering, M., \& Simon, G. (2004). Toward a mechanistic psychology of dialogue. Behavioral and Brain Sciences, 27(2), 169-226. https://doi.org/10.1017/S0140525X04000056

Pickering, M., \& Simon, G. (2006). Alignment as the basic for successful communication. Research on Language and Computation, 4, 203-228. https://doi.org/10.1007/s11168-006-9004-0

Plakans, L. (2008). Comparing composing processes in writing-only and reading-to-write test tasks. Assessing Writing, 13(2), 111-129. https://doi.org/10.1016/j.asw.2008.07.001

Pyun, D., \& Angela, L. S. (2011). Reducing Korean heritage language learners' orthographic errors: the contribution of online and in-class dictation and form-focused instruction. Language, Culture and Curriculum, 24(2), 141-158. https://doi.org/10.1080/07908318.2011.582952 
Qu, T. (2012). The effectiveness of dictation method in college English vocabulary teaching. Theory and Practice in Language Studies, 2(7), 1472-1476. https://doi.org/10.4304/tpls.2.7.1472-1476

Rahimi, M. (2008). Using dictation to improve language proficiency. The Asian EFL Journal, 10(1), 33-47.

Robinson, P., Alison, M., Susan, G., \& Richard, S. (2012). Attention and awareness in second language acquisition. In S. Gass, \& A. Mackey (Eds.), The Routledge Handbook of Second Language Acquisition, (pp. 247-267). London: Rouledge.

Savignon, S. (1982). Dictation as a measure of communicative competence in French as a second language. Language Learning, 32(1), 33-51. https://doi.org/10.1111/j.1467-1770.1982.tb00517.x

Shen, H. (2004). Level of cognitive processing: effects on character learning among non-native learners of Chinese as a foreign language. Language and Education, 18(2), 167-182. https://doi.org/10.1080/09500780408666873

Stansfield, C. (1985). A history of dictation in foreign language teaching and testing. The Modern Language Journal, 69(2), 121-128. https://doi.org/10.1111/j.1540-4781.1985.tb01926.x

Taylor, C. (1980). Dictation as a test of English proficiency. RELC Journal, 11(2), 88-92. https://doi.org/10.1177/003368828001100207

Wang. C. M. (2003). The compensation hypothesis in L2 learning. Foreign Language Research, 112(1), 1-5.

Wang, C. M. (2012). The continuation task---An effective method in enhancing foreign language acquisition. Foreign Language World, 152(5), 2-7.

Wang, C. M., \& Min, W. (2015). Effect of Alignment on L2 written production. Applied Linguistics, 36(5), 503-526. https://doi.org/10.1093/applin/amt051

Wang, M., \& Wang, C. M. (2014). The effects of alignment in continuation task. Modern Foreign Languages, 37(4), 501-512.

Zhang, X. Y. (2017). Reading-writing integrated tasks, comprehensive corrective feedback, and EFL writing development. Language Teaching Research, 21(2), 1-25. https://doi.org/10.1177/1362168815623291

Zwaan, R., \& Gabriel, R. (1998). Situation models in language comprehension and memory. Psychological Bulletin, 123(2), 162-185. https://doi.org/10.1037/0033-2909.123.2.162

Xue, H. H. (2013). Interest-related alignment in L2 story continuation. Guangdong University of Foreign Studies MA thesis.

Yan, Y. (2013). An Investigation in Chinese character cognitive mode and processing units of Elementary learners with Alphabetic-writing background. Chinese Language Learning, 3, 77-83.

\section{Copyrights}

Copyright for this article is retained by the author(s), with first publication rights granted to the journal.

This is an open-access article distributed under the terms and conditions of the Creative Commons Attribution license (http://creativecommons.org/licenses/by/4.0/). 